\title{
HUBUNGAN INDEKS MASSA TUBUH IBU DAN PENINGKATAN BERAT BADAN SAAT KEHAMILAN DENGAN PREEKLAMPSIA
}

\author{
${ }^{1}$ Hermanto Quedarusman \\ ${ }^{2}$ John Wantania \\ ${ }^{2}$ Juneke J. Kaeng
}

\author{
${ }^{1}$ Kandidat Skripsi Fakultas Kedokteran Unsrat Manado \\ ${ }^{2}$ Bagian Obstetri dan Ginekologi Fakultas Kedokteran Unsrat RSUP Prof. Dr. R.D Kandou \\ Manado \\ Email:niceguy_anto@yahoo.co.id
}

\begin{abstract}
Preeclampsia is a health problem that occurs when a pregnancy reaches 20 weeks or more, preeclampsia is accompanied by hypertension and protenuria as main signs. Women with obesity before pregnancy are known to have higher risk to get preeclampsia during pregnancy than those with normal IMT. Excessive weight gain during pregnancy can also increase the risk of preeclampsia in pregnant woman. The purpose of this research is to examine the relationship between maternal body mass index and weight gain during pregnancy with preeclampsia.This research used observasional-analytic method through case-control approach. The number of case group is 38 people and the number of control group is 38 people. The result shows that at risk women were four times more likely to develop preeclampsia during pregnancy than those with normal IMT (OR=4,32 95\% CI= 1,15-16,12), and obese women were five times more likely to develop preeclampsia during pregnancy than those with normal IMT $(\mathrm{OR}=5,06$ 95\% CI= 1,4612,67). The result also shows that women with excessive weight gain during pregnancy were almost three times more likely to develop preeclampsia during preeclampsia than women with normal weight gain during pregnancy $(\mathrm{OR}=2,5395 \% \mathrm{IK}=0,99-31,81)$. The results show that there is a significant association between maternal IMT and weight gain during pregnancy with preeclampsia.
\end{abstract}

Key Word: BMI, obesity, pregnancy and preeclampsia

\begin{abstract}
Abstrak: Preeklampsia adalah masalah kesehatan yang terjadi pada usia kehamilan 20 minggu ke atas dengan tanda utama hipertensi dan protenuria. Wanita dengan obesitas sebelum kehamilan memiliki risiko lebih besar untuk menderita preeklampsia dibandingkan wanita normal. Peningkatan berat badan berlebihan saat kehamilan juga dapat meningkatkan risiko terjadinya preeklampsia pada wanita hamil. Tujuan dari penelitian ini yaitu untuk mengetahui hubungan antara indeks massa tubuh (IMT) ibu dan peningkatan berat badan saat kehamilan dengan preeklampsia. Penelitian ini menggunakan metode observasional-analitik dengan desain case-control. Jumlah sampel untuk kelompok kasus 38 orang dan untuk kelompok kontrol 38 orang. Hasil dalam penelitian ini menunjukkan bahwa kelompok IMT at risk berisiko empat kali lebih besar untuk menderita preeklampsia dibandingkan kelompok IMT normal $(\mathrm{OR}=4,32$ 95\% IK= 1,15-16,12), sedangkan kelompok IMT obesitas berisiko lima kali lebih besar untuk menderita preeklampsia dibandingkan kelompok IMT normal (OR= 5,06 95\% IK=1,46-12,67). Kelompok dengan peningkatan berat badan tinggi berisiko hampir tiga kali lebih besar untuk menderita preeklampsia dibandingkan wanita dengan peningkatan berat badan saat hamil normal $(\mathrm{OR}=2,5395 \% \mathrm{IK}=0,99-31,81)$. Hasil penelitian ini menunjukkan bahwa terdapat hubungan bermakna antara indeks massa tubuh ibu dan peningkatan berat badan saat kehamilan dengan preeklampsia.
\end{abstract}

Kata Kunci: IMT, obesitas, kehamilan, dan preeklampsia. 
Preeklampsia adalah masalah kesehatan yang terjadi setelah 20 minggu kehamilan yang ditandai dengan adanya hipertensi dan proteinuria. ${ }^{1}$ Preeklampsia diperkirakan terjadi pada 5\% kehamilan. Preeklampsia kemudian dapat berkembang menjadi eklampsia yang dapat menyebabkan kematian maternal dan janin. Pada negara sedang berkembang kejadian eklampsia dilaporkan berkisar antara $0,3 \%$ sampai $0,7 \%$, sedang di negara-negara maju angka kejadian diketahui lebih kecil, yaitu 0,05\% sampai 0,1\%. Berdasarkan Depkes RI 2005, dilaporkan bahwa 50.000 ibu meninggal dunia karena preeklampsia dan eklampsia. Insiden preeklampsia dan preeklampsia berat (PEB) berkisar antara 1:1000 sampai $1: 1700 .^{2,3}$

Overweight dan obesitas merupakan risiko terbesar kelima yang dapat menyebabkan kematian global. Suatu penelitian dilakukan oleh Anjel di Amerika Serikat pada wanita usia subur menunjukkan bahwa 24,5\% wanita usia 20-44 tahun memiliki status gizi overweight dan 23\% di antaranya obes. ${ }^{4,5}$

Penelitian yang dilakukan oleh Matthias $\mathrm{dkk}^{6}$ menunjukkan bahwa pola diet termasuk konsumsi berlebihan daging merah, gandum, dan makanan pencuci mulut yang manis, dan kentang mungkin berkontribusi dalam terjadinya peningkatan berat badan jangka panjang. Berat badan bisa dikatakan ideal jika berat badan tersebut bisa memberikan pengaruh positif yang maksimal bagi kesehatan.

Penelitian yang dilakukan oleh James $\mathrm{dkk}^{8}$ menyatakan bahwa berat badan berlebihan pada wanita hamil berhubungan dengan preeklampsia. Pada penelitian lain yang dilakukan Mark $\mathrm{dkk}^{9}$, dikatakan bahwa obesitas pada kehamilan berhubungan dengan peningkatan morbiditas pada ibu dan bayi.

Studi di suatu populasi obstetrik yang besar menunjukkan timbulnya peningkatan risiko terjadinya gangguan antenatal, intrapartum, dan postpartum pada sampel yang mengidap overweight dan obesitas. ${ }^{10}$ Frederick $\mathrm{dkk}^{11}$ menemukan bahwa setiap peningkatan IMT sebelum kehamilan menyebabkan peningkatan risiko preeklampsia sebesar 8\%. Semua penelitian sebelumnya ini dilakukan dengan menggunakan standar IMT secara umumnya, dan belum ada penelitian yang dilakukan dengan menggunakan standar IMT pada orang Asia sehingga tidak diketahui bagaimana pengaruh kedua faktor tersebut terhadap orang Asia.

Penelitian sebelumnya kurang lebih memperlihatkan hubungan antara indeks massa tubuh dan peningkatan berat badan pada kehamilan. Hal ini mendorong peneliti untuk melakukan penelitian untuk melihat hubungan tersebut lebih lanjut di puskesmas di Manado.

\section{METODE PENELITIAN}

Metode penelitian ini merupakan observasional-analitik dengan desain penelitian case-control. Penelitian ini dilakukan dengan mengambil sampel dari empat puskemas di Manado yaitu di puskesmas Bahu, Teling Atas, Kombos, dan Tuminting. Penelitian ini dilakukan dari bulan November sampai Desember 2012.

Populasi pada penelitian ini adalah wanita hamil berusia 18-40 tahun yang menjadi pasien di puskemas Manado yang menjadi tempat penelitian. Sampel dihitung dengan menggunakan rumus case-control berpasangan dan didapatkan jumlah sampel 38 untuk kelompok kasus dan 38 untuk kelompok kontrol.

Kelompok kasus pada penelitian ini adalah wanita hamil yang didiagnosis dengan preeklampsia. Kelompok kontrol pada penelitian ini adalah wanita hamil normal. Preeklampsia diklasifikasikan menjadi preeklampsia ringan dan berat. Preeklampsia berat dibagi pula menjadi preeklampsia berat tanpa impending eclampsia dan preeklampia dengan impending eclampsia. Preeklampsia ringan meliputi $75 \%$ dari kasus preeklampsia, sedangkan preeklampsia berat meliputi 25\% kasus sisanya. ${ }^{12-14}$ Namun, penelitian ini tidak memisahkan sampel dalam preeklampsia ringan maupun berat. Data yang dikumpulkan berupa data sekunder 
yang didapatkan dari kartu pemeriksaan kehamilan di puskesmas.

Variabel bebas penelitian berupa indeks massa tubuh ibu kunjungan 16 minggu dan peningkatan berat badan ibu yang berupa selisih dari berat badan ibu kunjungan $\geq 36$ minggu dan $\leq 16$ minggu. Variabel terikat dalam penelitian ini merupakan kejadian preeklampsia.

Pada penelitian ini indeks massa tubuh ibu dibagi menjadi tiga kelompok yaitu kelompok underweight dan normal $(<18,5-$ $22,9 \mathrm{~kg} / \mathrm{m}^{2}$ ), kelompok at risk (23-24,9 $\mathrm{kg} / \mathrm{m}^{2}$ ), dan kelompok obesitas yang mengabungkan obes I dan obes $\geq$ प्र5 ( $\mathrm{kg} / \mathrm{m}^{2}$ ). Kategori ini berdasarkan pada kriteria indeks massa tubuh WHO pada orang Asia. ${ }^{15}$

Tabel 1 menunjukkan kategori peningkatan berat badan ibu saat kehamilan juga dibagi menjadi tiga kelompok, yaitu kelompok rendah, sedang dan tinggi. Peningkatan berat badan ibu saat kehamilan yang normal didasarkan pada besar IMT ibu sebelum kehamilan. ${ }^{16}$

Data yang telah diperoleh kemudian diproses dengan menggunakan program SPSS 20. Analisis yang dilakukan merupakan analisis univariat dan analisis bivariat, yaitu analisis chi-square.

\section{HASIL PENELITIAN}

Usia subjek penelitian pada kelompok kasus berkisar antara 18-38 tahun. IMT pada kelompok kasus berkisar antara 20,34-32,46 kg/m². IMT pada kelompok kasus memiliki nilai rata-rata 25,4589 kg/m².
Usia pada kelompok kontrol berkisar 20-40 tahun. IMT pada kelompok kontrol berkisar antara $15,28-28,72 \mathrm{~kg} / \mathrm{m}^{2}$ dengan nilai ratarata $22,1199 \mathrm{~kg} / \mathrm{m}^{2}$.

Tabel 2 menunjukkan data IMT kelompok kasus. Data tersebut menunjukkan bahwa subjek penelitian umumnya masuk dalam kelompok IMT 25-29,9 $\mathrm{kg} / \mathrm{m}^{2}$ atau obese I.

Tabel 2. Data IMT kelompok kasus

\begin{tabular}{ccc}
\hline IMT $\left(\mathrm{kg} / \mathrm{m}^{2}\right)$ & Frekuensi & Persentasi (\%) \\
\hline$<18,5$ & 0 & 0 \\
$18,5-22,9$ & 10 & 26,32 \\
$23-24,9$ & 9 & 23,68 \\
$25-29,9$ & 14 & 36,84 \\
$\geq 30$ & 5 & 13,16 \\
Total & 38 & 100 \\
\hline
\end{tabular}

Tabel 3 menunjukkan data IMT kelompok kontrol. Data tersebut menunjukkan bahwa subjek penelitian umumnya masuk dalam kelompok IMT 18,5-22,9 $\mathrm{kg} / \mathrm{m}^{2}$ atau normal.

Tabel 3. Data IMT kelompok kontrol

\begin{tabular}{ccc}
\hline $\begin{array}{c}\text { IMT } \\
\left(\mathbf{k g} / \mathbf{m}^{\mathbf{2}}\right)\end{array}$ & Frekuensi & $\begin{array}{c}\text { Persentasi } \\
\mathbf{( \% )}\end{array}$ \\
\hline$<18,5$ & 5 & 13,16 \\
$18,5-22,9$ & 19 & 50 \\
$23-24,9$ & 5 & 13,16 \\
$25-29,9$ & 9 & 23,68 \\
$\geq 30$ & 0 & 0 \\
Total & 38 & 100 \\
\hline
\end{tabular}

Tabel 1. Kategori peningkatan berat badan saat kehamilan berdasarkan IMT

\begin{tabular}{ccccc}
\hline & \multicolumn{4}{c}{ Kategori Peningkatan Berat Badan saat Kehamilan berdasarkan } \\
& \multicolumn{4}{c}{ IMT $(\mathrm{kg})$} \\
\cline { 2 - 5 } & $\mathrm{IMT}<18,5$ & $\mathrm{IMT} \mathrm{18,5-24,9}$ & $\mathrm{IMT} 25-29,9$ & $\mathrm{IMT} \geq 30$ \\
$\mathrm{~kg} / \mathrm{m}^{2}$ & $\mathrm{~kg} / \mathrm{m}^{2}$ & $\mathrm{~kg} / \mathrm{m}^{2}$ & $\mathrm{~kg} / \mathrm{m}^{2}$ \\
\hline Rendah & $<12,5$ & $<11,5$ & $<7$ & $<5$ \\
Sedang & $12,5-17$ & $11,5-16$ & $7-11,5$ & $5-9$ \\
Tinggi & $>17$ & $>16$ & $>11,5$ & $>9$ \\
& & & & \\
\hline
\end{tabular}

IMT = Indeks Massa Tubuh 
Tabel 4 menunjukkan data peningkatan berat badan saat kehamilan pada kelompok kasus. Data tersebut menunjukkan bahwa mayoritas subjek penelitian yang mengalami peningkatan berat badan tinggi adalah kelompok IMT 25-29,9 kg/m².

Tabel 4. Data peningkatan berat badan ibu saat kehamilan pada kelompok kasus

\begin{tabular}{|c|c|c|c|}
\hline $\begin{array}{c}\text { IMT } \\
\left(\mathrm{kg} / \mathrm{m}^{2}\right)\end{array}$ & $\begin{array}{c}\text { Peningkatan } \\
\text { Berat Badan } \\
\text { saat hamil } \\
\text { (kg) }\end{array}$ & Frekuensi & $\begin{array}{c}\text { Persentasi } \\
\text { (\%) }\end{array}$ \\
\hline \multirow[t]{3}{*}{$<18,5$} & $<12,5$ & 0 & 0 \\
\hline & $12,5-18$ & 0 & 0 \\
\hline & $>18$ & 0 & 0 \\
\hline \multirow{4}{*}{$\begin{array}{l}18,5- \\
24,9\end{array}$} & $<11,5$ & 11 & 28,95 \\
\hline & $11,5-16$ & 4 & 10,53 \\
\hline & $>16$ & 4 & 10,53 \\
\hline & $<7$ & 1 & 2,63 \\
\hline \multirow[t]{3}{*}{$25-29,9$} & $7-11,5$ & 8 & 21,05 \\
\hline & $>11,5$ & 5 & 13,15 \\
\hline & $<5 \mathrm{~kg}$ & 1 & 2,63 \\
\hline \multirow[t]{3}{*}{$\geq 30$} & $5-9 \mathrm{~kg}$ & 4 & 10,53 \\
\hline & $>9 \mathrm{~kg}$ & 0 & 0 \\
\hline & Total & 38 & 100 \\
\hline
\end{tabular}

Tabel 5. Data peningkatan berat badan ibu saat kehamilan pada kelompok kontrol

\begin{tabular}{|c|c|c|c|}
\hline $\begin{array}{c}\text { IMT } \\
\left(\mathrm{kg} / \mathrm{m}^{2}\right)\end{array}$ & $\begin{array}{c}\text { Peningkatan } \\
\text { Berat Badan } \\
\text { saat Hamil } \\
\text { (kg) } \\
\end{array}$ & Frekuensi & $\begin{array}{c}\text { Persentasi } \\
(\%)\end{array}$ \\
\hline 18,5 & $\begin{array}{c}<12,5 \\
12,5-18 \\
>18\end{array}$ & $\begin{array}{l}3 \\
2 \\
0\end{array}$ & $\begin{array}{c}7,89 \\
5,26 \\
0\end{array}$ \\
\hline $\begin{array}{c}18,5- \\
24,9\end{array}$ & $\begin{array}{c}<11,5 \\
11,5-16 \\
>16\end{array}$ & $\begin{array}{c}20 \\
4 \\
0\end{array}$ & $\begin{array}{c}52,64 \\
10,53 \\
0\end{array}$ \\
\hline $25-29,9$ & $\begin{array}{c}<7 \mathrm{~kg} \\
7-11,5 \mathrm{~kg} \\
>11,5 \mathrm{~kg}\end{array}$ & $\begin{array}{l}4 \\
3 \\
2\end{array}$ & $\begin{array}{c}10,53 \\
7,89 \\
5,26\end{array}$ \\
\hline$\geq 30$ & $\begin{array}{l}<5 \mathrm{~kg} \\
5-9 \mathrm{~kg} \\
>9 \mathrm{~kg}\end{array}$ & $\begin{array}{l}0 \\
0 \\
0\end{array}$ & $\begin{array}{l}0 \\
0 \\
0\end{array}$ \\
\hline & Total & 38 & 100 \\
\hline
\end{tabular}

Tabel 5 menunjukkan data peningkatan berat badan saat kehamilan pada kelompok kontrol. Data pada kelompok kontrol menunjukkan bahwa kelompok yang paling banyak mengalami peningkatan berat badan saat kehamilan tinggi adalah kelompok IMT 25-29,9 kg/m².

Analisis chi-square kemudian dilakukan untuk melihat hubungan antara IMT ibu dan preeklampsia seperti tabel 6 di bawah ini, dan kemudian diperoleh nilai signifikansi $\mathrm{p}<0.05$ yaitu 0,005 .

Tabel 6. Analisis hubungan IMT ibu dan preeklampsia

\begin{tabular}{|c|c|c|c|c|c|}
\hline \multicolumn{3}{|c|}{ Status gizi Preeklampsia } & \multirow{2}{*}{$\begin{array}{l}\text { To- } \\
\text { tal }\end{array}$} & \multirow{2}{*}{$\mathbf{P}$} & \multirow[t]{2}{*}{ OR(95\% IK) } \\
\hline responden & Tidak & Ada & & & \\
\hline $\begin{array}{l}\text { under- } \\
\text { weight }\end{array}$ & 24 & 10 & 34 & & Referensi \\
\hline at risk & 5 & 9 & 14 & 0,005 & $\begin{array}{c}4,32(1,15- \\
16,12)\end{array}$ \\
\hline obes & 9 & 19 & 28 & & $\begin{array}{c}5,06(1,46- \\
12,67)\end{array}$ \\
\hline Total & 38 & 38 & 76 & & \\
\hline
\end{tabular}

Tabel 7. Analisis hubungan peningkatan berat badan saat kehamilan dengan preeklampsia

\begin{tabular}{lccccc}
\hline $\begin{array}{l}\text { Status gizi } \\
\text { responden }\end{array}$ & Tidak & Ada & Total & P & OR(95\% IK) \\
\hline $\begin{array}{c}\text { under- } \\
\text { weight }\end{array}$ & 24 & 10 & 34 & & Referensi \\
at risk & 5 & 9 & 14 & 0,005 & $\begin{array}{c}4,32(1,15- \\
16,12)\end{array}$ \\
& & & & & $\begin{array}{c}\text { (2),06 }(1,46- \\
12,67)\end{array}$ \\
obesitas & 9 & 19 & 28 & & \\
Total & 38 & 38 & 76 & &
\end{tabular}

Analisis chi-square juga dilakukan untuk melihat hubungan antara peningkatan berat badan ibu saat kehamilan dengan preeklampsia seperti ditunjukkan tabel 7 . Dari hasil analisis tersebut diperoleh bahwa nilai signifikansi $<0,05$, yaitu 0,003 . 


\section{PEMBAHASAN}

Pada penelitian ini, didapatkan bahwa pada kelompok kasus terutama tergolong dalam kelompok obes I (25-29,9 kg/m²) yaitu berjumlah 14 orang atau sekitar 36,84\% dari keseluruhan subjek penelitian di kelompok kasus. Hasil ini memiliki perbedaan dengan penelitian sebelumnya yang dilakukan oleh Roberta $\mathrm{dkk}^{17}$, yaitu pada penelitian tersebut didapatkan sekitar $15 \%$ subjek penelitian kelompok kasus yang masuk di kelompok overweight dan obesitas. Perbedaan ini dapat disebabkan karena jumlah sampel dalam penelitian sebelumnya yang besar yaitu 481 orang.

Data IMT pada kelompok kontrol menunjukkan bahwa 50\% subjek masuk dalam kelompok IMT normal (18,5-22,9 $\mathrm{kg} / \mathrm{m}^{2}$ ). Hasil ini sesuai dengan penelitian yang dilakukan oleh Roberta $\mathrm{dkk}^{16}$, dimana pada penelitian tersebut didapati $77,7 \%$ dari keseluruhan subjek penelitian dengan kehamilan normal masuk dalam kelompok IMT normal.

Data peningkatan berat badan ibu saat kehamilan pada kelompok kasus menunjukkan bahwa subjek penelitian yang masuk kelompok obes I (25-29,9 kg/m²) merupakan kelompok yang paling banyak mengalami peningkatan berat badan tinggi $(>11,5 \mathrm{~kg})$ yaitu $13,15 \%$. Penelitian sebelumnya oleh Mbah dkk ${ }^{18}$ menunjukkan bahwa kebanyakan wanita hamil mengalami peningkatan berat badan sedang yaitu $88,2 \%$. Perbedaan bisa disebabkan karena jumlah sampel yang besar pada penelitian sebelumnya yaitu 837.912 orang.

Data peningkatan berat badan saat kehamilan pada kelompok kontrol menunjukkan bahwa pada kelompok IMT $18,5-24,9 \mathrm{~kg} / \mathrm{m}^{2}$ umumnya mengalami peningkatan berat badan rendah (52,64 \%). Hasil ini berbeda dengan penelitian sebelumnya yang dilakukan oleh Mbah $\mathrm{dkk}^{18}$ yang menunjukkan bahwa wanita hamil umumnya mengalami peningkatan berat badan sedang yaitu 88,2\%. Perbedaan ini juga dapat disebabkan karena perbedaan jumlah sampel yang signifikan antara penelitian ini dan penelitian sebelumnya.
Hasil analisis chi-square menolak hipotesis nol $(P=0,005)$ sehingga menunjukkan adanya hubungan antara IMT Ibu dengan preeklampsia. Dari hasil analisis, didapatkan bahwa subjek penelitian yang masuk kelompok IMT at risk (23-24,9 kg/m²) memiliki risiko empat kali lebih besar untuk menderita preeklampsia saat hamil dibandingkan dengan subjek penelitian yang masuk kelompok underweight dan normal (OR= 4,32 95\% $\mathrm{IK}=1,15-16,12)$. Subjek penelitian yang masuk kelompok IMT obesitas memiliki risiko lima kali lebih besar untuk menderita preeklampsia saat hamil dibandingkan dengan subjek penelitian yang underweight dan normal $(\mathrm{OR}=5,06$ 95\% $\mathrm{IK}=1,46-$ 12,67). Hal ini sesuai dengan penelitian sebelumnya yang dilakukan oleh Mbah $\mathrm{dkk}^{18}$ yang menunjukkan bahwa wanita dengan obesitas sebelum kehamilan memiliki risiko lebih besar untuk mengalami preeklampsia dibandingkan dengan wanita dengan IMT normal.

Pada penelitian kali ini terdapat perbedaan dibandingkan penelitian sebelumnya. Penelitian yang sebelumnya menunjukkan bahwa wanita hamil dengan obesitas memiliki risiko tiga kali lebih besar untuk mengalami preeklampsia dibandingkan dengan mereka yang normal. ${ }^{18}$ Hal ini bisa disebabkan karena bedanya metode yang digunakan dimana pada penelitian yang sebelumnya mengesampingkan wanita yang tergolong underweight dan overweight. Penelitian kali ini juga menggunakan standar IMT untuk orang Asia, sedangkan penelitian sebelumnya menggunakan standar IMT untuk nonAsia.

Salah satu penelitian sebelumnya juga yang dilakukan oleh Sarah dkk $^{19}$ menunjukkan bahwa wanita dengan obesitas kelas II dan III memiliki risiko tiga sampai empat kali lebih besar untuk menderita preeklampsia ringan dibandingkan wanita normal. Penelitian tersebut juga memiliki hasil yang sesuai dengan penelitian sekarang.

Hasil analisis chi-square menunjukkan terdapat hubungan bermakna antara 
peningkatan berat badan ibu saat kehamilan dengan preeklampsia $(P=0,003)$. Melalui penelitian ini, didapatkan bahwa pada wanita dengan peningkatan berat badan rendah saat hamil memiliki kemungkinan 0,27 kali untuk menderita preeklampsia dibandingkan wanita yang peningkatan berat badannya normal $(\mathrm{OR}=0,2795 \% \mathrm{IK}=$ 0,11-0,86). Pada wanita dengan peningkatan berat badan tinggi berisiko hampir tiga kali lebih besar untuk menderita preeklampsia saat hamil dibandingkan wanita yang peningkatan berat badan saat hamilnya normal $(\mathrm{OR}=2,53$ 95\% IK=0,9931,81). Penelitian ini menunjukkan kelemahan di Odd ratio wanita hamil dengan peningkatan berat badan tinggi dan wanita hamil normal menunjukkan bahwa interval kepercayaannya memiliki nilai ambigu positif dan negatif. Jika nilai minimum dari odd ratio kurang dari satu, maka peningkatan berat badan tinggi bisa merupakan faktor yang dapat mengurangi risiko terjadinya preeklampsia pada wanita hamil. Nilai interval kepercayaan ini menunjukkan perlunya penelitian ulang.

Dalam kedua analisis pada penelitian ini terdapat beberapa keterbatasan, antara lain:

1. Kemungkinan bias, penelitian ini tidak memperhitungkan kemungkinan hubungan jumlah paritas dan kebiasaan pasien seperti merokok dengan preeklampsia.

2. Data yang terdapat di kartu pemeriksaan ibu hamil juga tidak menunjukkan diagnosis preeklampsia yang jelas seperti preeklampsia berat dan ringan.

3. Penelitian ini tidak melakukan analisis hubungan peningkatan berat badan ibu saat kehamilan dengan preeklampsia pada tiap-tiap kelompok IMT karena jumlah sampel yang sedikit.

4. Jumlah sampel yang sedikit juga memperlebar interval kepercayaan pada tiap-tiap odd ratio.

\section{SIMPULAN}

Terdapat hubungan antara indeks massa tubuh ibu dan peningkatan berat badan saat kehamilan dengan preeklampsia.

\section{UCAPAN TERIMA KASIH}

Penulis berterima kasih pada dr. Rudy Lengkong, SpOG-K, dr. Maria Loho, SpOG-K, dan berbagai pihak lain yang telah membantu dalam menyelesaikan artikel ini.

\section{DAFTAR PUSTAKA}

1. Bodnar L, Ness R, Harger G, dan Roberts J. Inflammation and triglycerides partially mediate the effect of prepregnancy body mass index on the risk of preeclampsia. American Journal of Epidemiology. 2005;162:1198-1206.

2. Hubungan paritas dan usia ibu dengan kejadian preeklampsia berat (PEB) [Internet]. 2012 [updated 2012 Febdiperbaharui 13 Februari 2012; dikutip 1 September 2012). Diunduh dari: http://www.ktiskripsi.net/2012/02/hubungan-paritas-danusia-ibu-dengan.html.

3. Djannah S dan Arianti I. Gambaran epidemiologi kejadian preeklampsia/ eklampsia di RSU Pku Muhammadiyah Yogyakarta tahun 2007-2009. Universitas Ahmad Dahlan. 2010;13(4):378-385.

4. Obesity and overweight [homepage on the Internet]. 2012 [cited 2012 Sep 01]. Available from: http://www.who.int/media centre/factsheets/fs311/en/index.html.

5. Vahratian A. Prevalence of overweight and obesity among women of childbearing age: results from the 2002 National Survey of Family Growth. Matern Child Health J. 2009;13:268-273.

6. Schulze M, Fung T, Manson J, Willett W, dan Hu F. Dietary patterns and changes in body weight in woman. OBESITY. 2006;14:1444-1453.

7. Ideal body weight (IBW) [homepage on the Internet]. 2006 [cited 2012 Sep 01]. Available from: http://www.medilexicon. com/medicaldictionary.php.

8. Robert $J$, Bodnar $L$, Patrick $T$, dan Powers R. The role of obesity in preeclampsia. Pregnancy Hypertens. 2011;1(1):6-16.

9. Alanis $M$, Goodnight $W$, Hill $E$, Robinson C, Villers M, Johnson D. 
Maternal super-obesity (body mass index $\geq$ 50) and adverse pregnancy outcomes. Acta Obstetricia et Gynecologica. 2010;89:924930.

10. Madan J, Chen M, Goodman E, Davis J, dan Dammann O. Maternal obesity, gestational hypertension, and preterm delivery. The Journal of Maternal-Fetal and Neonatal Medicine. 2010;23(1):82-8.

11. Guelinckx I, Devliegers R, Beckers K, Vansant G. Maternal obesity: Pregnancy complication, gestational weight gain, and nutrition. The International Association for the Study of Obesity. Obesity reviews. 2008;9:140-60.

12. Saifuddin A, Rachimhadi T, Wiknjosastro G, editor. Ilmu kebidanan Sarwono Praworohardjo (Edisi Keempat). Jakarta: P.T. Bina Pustaka Sarwono Prawirohardjo; 2008. p.532-45.

13. Profitasari, Hartanto $H$, Suyono $J$, Yusna D, Kosasih A, Prawira J, et al, editor. Obstetri Williams volume 1 (Edisi ke-21). Jakarta: Penerbit Buku Kedokteran EGC, 2004; p.627-31.

14. Lim Kee. Preeclampsia [homepage on the Internet]. 2011 [updated 2011 Nov 10; cited 2012 Oct 30). Available from: www.emedicine-medscape.com.

15. Sudoyo A, Setiyohadi B, Alwi I, Simadibrata M, Setiati S. Buku Ajar Ilmu Penyakit Dalam jilid III (Edisi Kelima). Jakarta: Interna Publishing, 2009; p.1977-8.

16. Healthy weight gain during pregnancy [homepage on the Internet]. 2010 [cited 2012 Sep 17]. Available from: http://www.health.qld.gov.au/masters/copy right.asp.

17. Ness R, Zhang $\mathbf{J}$, Bass $D$, Klebanoff $M$. Interactions between smoking and weight in pregnancies complicated by preeclampsia and small-for-gestational-age birth. American Journal of Epidemiology. 2008;168:427-433.

18. Mbah A, Kornosky J, Kristensen S, August E, Alio A, Marty P, et al. Superobesity and risk for early and late preeclampsia. An International Journal of Obstetrics and Gynaecolog. 2010;117:997100.

19. Sohlberg S, Stephansson O, Cnattingius S, Wikström A. Maternal body mass index, height, and risks of preeclampsia. American Journal of Hypertension, 2012; 25(1):120-125. 